Vietnam Academy of Science and Technology
Vietnam Journal of Earth Sciences
Website: http://www.vjs.ac.vn/index.php/jse

\title{
Finite element method in estimation of lag time of rainfall recharge to Holocene groundwater aquifer in Hung Yen province
}

\author{
Nguyen Van Hoang*, Nguyen Duc Roi \\ Institute of Geological Sciences, Vietnam Academy of Science and Technology
}

Accepted 20 December 2015

\begin{abstract}
In the Red River delta, Holocene aquifer has main recharge from rainfall and irrigation. The recharge is much dependent upon the unsaturation-saturation condition of the semipermeable layer covering the aquifer. The paper presents the analysis of moisture transfer in this covering semipermeable layer to estimate the lag time of rainfall recharge to the Holocene aquifer in Hung Yen province in the Red River delta. A finite element modeling had been developed and applied for this purpose. The lag time results have been based on the condition that the degree of saturation of $90 \%$ or more is representative for saturation water movement, and therefore the rainfall is actually recharging the aquifer via saturated flow through the covering semipermeable layer. The lag time is 3 days for continuous wet condition from the rainfall if the thickness of the semipermeable layer is $2 \mathrm{~m}$, and 5.5 days if the thickness is $3 \mathrm{~m}$. For consecutive wet day and dry day condition the lag time is 4 days if the thickness is $2 \mathrm{~m}$ and 13 days if the thickness is $3 \mathrm{~m}$. Therefore, the duration of rainfall for recharge estimation for the study area would be up to about two weeks.
\end{abstract}

Keywords: Red River Plain, Groundwater, Holocene Aquifer, Groundwater Recharge, Pearson Correlation, Moisture Transfer, Finite Element Method, Lag Time.

C2015 Vietnam Academy of Science and Technology

\section{Introduction}

As it is well known that rainfall plays a significant role in recharging first aquifer from the ground surface in the Red river plain. Also, in water resources development, it is important to determine the dynamic reserve of aquifer from the rainfall recharge for sustainable groundwater (GW) resources exploitation. The time for which the infiltrated rainfall water reaches the first aquifer from the ground surface expresses how fast the recharge is in response to the rainfall, and therefore directly effects the recharge rate. This time duration is called lag time. Besides, the lag time shall allows to adopt the right rainfall

*Corresponding author, Email: N_V_Hoang_VDC@yahoo.com duration in analysis of the recharge from rainfall, for example, daily rainfall, or rainfall of several consecutive days, weekly rainfall, monthly rainfall, rainfall of several months etc.

For illustration, it can consider the GW level in Holocene aquifer in Nhu Quynh, Hung Yen province at monitoring GW well QT119 (Figure 1) and daily rainfall as shown in Figure 2 for daily rainfall and Figure 3 for monthly rainfall (Department of geology and mineral resourcesMoNRE. 2013; National Center for Meteorology and Hydrology-MoNRE, 2013). The Pearson correlation coefficient for the whole data series between GW level and daily rainfall is 0.129 (which means very poor correlation) and monthly rainfall is 0.574 (which means moderate correlation). However if considering the relationship between WG level and cumulative rainfall for duration during rainy 
N.V. Hoang and N.D. Roi/Vietnam Journal of Earth Sciences 37 (2015)

season from January to July 1995 then the daily cumulative rainfall gave Pearson correlation coefficient 0.828 and monthly cumulative rainfall gave Pearson correlation coefficient 0.7 . Therefore, between the GW level and rainfall obviously is a certain tight correlation for some rainfall of a certain rainfall duration. This issue is more suitable for statistical analysis rather than for physical modeling rainfall infiltration of the system. The lag time has more physical meaning for the rainwater infiltration physics than that of the duration of rainfall for which a good correlation is observed. The lag time is to be analyzed by the water movement in unsaturated soil by means of finite element modeling (FEM).

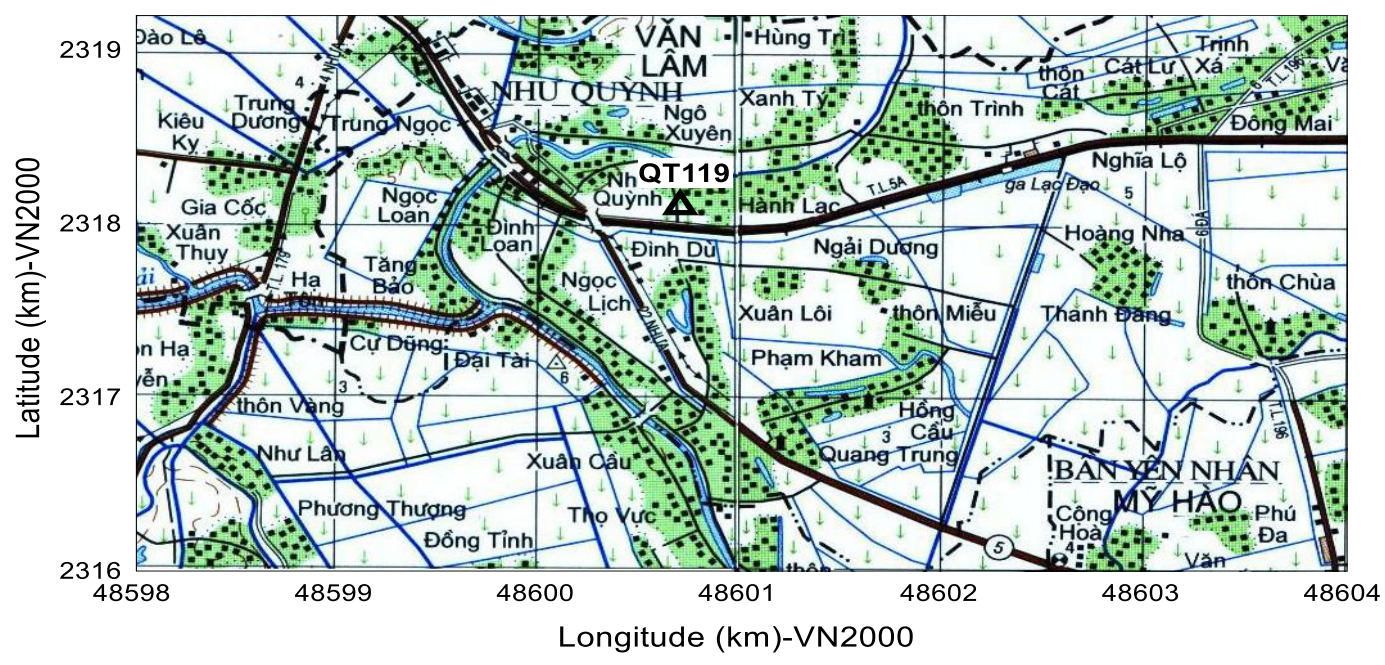

Fig. 1. Location of groundwater monitoring well QT119

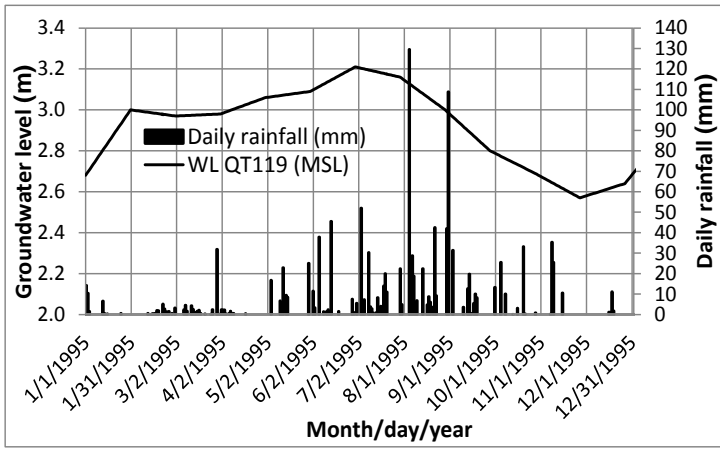

Fig. 2. GW level and daily rainfall in 1995

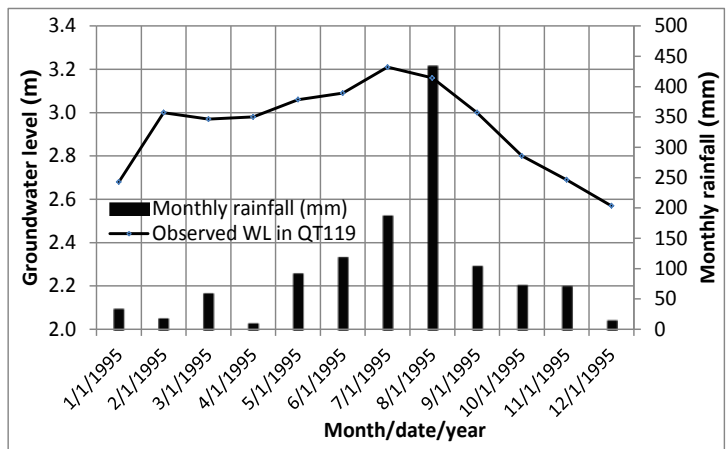

Fig. 3. GW level and monthly rainfall in 1995

\section{Unsaturated-saturated water flow}

As it is well known that for certain weather conditions, the soil below the ground surface is unsaturated, then rainwater on the ground may infiltrate into the depth. The partial diffrenetial equation describing water movement in unsaturated soils with the assumption that the air does not move (Jacob Bear and Arnold Verruijt, $1987)$ in three dimensional space $(x, y, z)$ has the following form (Polubarinova-Kochina, 1977):

$$
\frac{\partial v_{\mathrm{x}}}{\partial x}+\frac{\partial v_{\mathrm{y}}}{\partial y}+\frac{\partial v_{\mathrm{z}}}{\partial z}=-\frac{\partial \theta_{w}}{\partial t}
$$

in which: $\theta_{\mathrm{w}}$ is the soil moisture (volume amount of water in one unit volume of soil), $t$ is the time, $v_{x} ; v_{y}$ and $v_{z}$ moisture movement velocity in $x, y$ and $\mathrm{z}$ directions, respectively:

$$
\begin{gathered}
v_{x}=-K\left(\theta_{w}\right) \frac{\partial h}{\partial x} ; \quad v_{y}=-K\left(\theta_{w}\right) \frac{\partial h}{\partial y} ; \\
v_{z}=-K\left(\theta_{w}\right) \frac{\partial h}{\partial z}
\end{gathered}
$$


Vietnam Journal of Earth Sciences 37 (2015) 355-362

in which: $h=p / \gamma+z$ where $h$ is the water suction pressure; $p$ water pressure (or absolute suction head); $\gamma$ is water density, and $K\left(\theta_{w}\right)$ is the unsaturated hydraulic conductivity (as a specific function of saturated hydraulic conductivity and moisture content for a given soil).

From (1) and (2) its follows:

$$
\frac{\partial \theta_{w}}{\partial t}=\frac{\partial}{\partial x}\left(\frac{K\left(\theta_{w}\right)}{\gamma} \frac{\partial p}{\partial x}\right)+\frac{\partial}{\partial y}\left(\frac{K\left(\theta_{w}\right)}{\gamma} \frac{\partial p}{\partial y}\right)+\frac{\partial}{\partial z}\left(\frac{K\left(\theta_{w}\right)}{\gamma} \frac{\partial p}{\partial z}\right)+\frac{\partial K\left(\theta_{w}\right)}{\partial z}
$$

Since $p$ is a function of $\theta_{w}$, and if taking water two dimensions ( $x$-horizontal $z$-vertical) as density equal 1 we have (3) written in follows:

$$
\frac{\partial \theta_{w}}{\partial t}=\frac{\partial}{\partial x}\left(K\left(\theta_{w}\right) \frac{d p}{d \theta_{w}} \frac{\partial \theta_{w}}{\partial x}\right)+\frac{\partial}{\partial z}\left(K\left(\theta_{w}\right) \frac{d p}{d \theta_{w}} \frac{\partial \theta_{w}}{\partial z}\right)+\frac{\partial K\left(\theta_{w}\right)}{\partial z}
$$

The term $\left[K\left(\theta_{w}\right) \frac{d p}{d \theta_{w}}\right]$ is called moisture dispersion coefficient $D\left(\theta_{w}\right)\left(\mathrm{L}^{2} \mathrm{~T}^{-1}\right)$, then (4) has

$$
\frac{\partial \theta_{w}}{\partial t}=\frac{\partial}{\partial x}\left[D\left(\theta_{w}\right) \frac{\partial \theta_{w}}{\partial x}\right]+\frac{\partial}{\partial z}\left[D\left(\theta_{w}\right) \frac{\partial \theta_{w}}{\partial z}\right]+\frac{\partial K\left(\theta_{w}\right)}{\partial z}
$$

The relationship between $p$ (in $\mathrm{cm}$ ), $\theta_{w}$ and $\theta_{\text {sat }}$ usually has the form:

$$
p=A\left(\frac{\theta_{w}}{\theta_{\text {sat }}}\right)^{B}
$$

The relationship between unsaturated hydraulic conductivity (in $\mathrm{m} / \mathrm{s}$ ), $\theta_{w}$ and $\theta_{\text {sat }}$ has the form:

$$
K\left(\theta_{w}\right)=C\left(\frac{\theta_{w}}{\theta_{\text {sat }}}\right)^{D}
$$

Therefore, from (4), (5) and (6) we have moisture dispersion $D\left(\theta_{w}\right)\left(\right.$ in $\mathrm{m}^{2} / \mathrm{s}$ ) as (note that $\mathrm{B}<0)$ :

$$
\begin{aligned}
D\left(\theta_{w}\right)=K\left(\theta_{w}\right) \frac{\partial \theta_{w}}{\partial x} & =C\left(\frac{\theta_{w}}{\theta_{\text {sat }}}\right)^{D} \times A \times(-B) \frac{\theta_{w}^{B-1}}{\theta_{\text {sat }}^{B}}(8) \quad K\left(\theta_{w}\right)=1.33 \times 10^{-5}\left(\frac{\theta_{w}}{\theta_{\text {sat }}}\right)^{42.08} \\
D\left(\theta_{w}\right) & =8.33 \times 10^{-7}\left(\frac{\theta_{w}}{\theta_{\text {sat }}}\right)^{16.37} \times 9.462\left(\frac{\theta_{w}}{\theta_{\text {sat }}}\right)^{-6.70} \theta_{w} \leq 0.35 \\
D\left(\theta_{w}\right) & =1.33 \times 10^{-5}\left(\frac{\theta_{w}}{\theta_{\text {sat }}}\right)^{42.08} \times 2.4489\left(\frac{\theta_{w}}{\theta_{\text {sat }}}\right)^{-28.21} \quad \theta_{w}>0.35
\end{aligned}
$$

For reference, the parameters A, B, C and D in (8) for the tested soil by Hart (1972) (Jiunsheng Li và Hiroshi Kawano, 1997) the following relationships are observed:

$$
p=1.66\left(\frac{\theta_{w}}{\theta_{\text {sat }}}\right)^{-5.70} \quad \theta_{w} \leq 0.35
$$

$$
p=0.09\left(\frac{\theta_{w}}{\theta_{\text {sat }}}\right)^{-27.21} \quad \theta_{w^{\prime}}>0.35
$$

$$
\begin{array}{ll}
K\left(\theta_{w}\right)=8.33 \times 10^{-7}\left(\frac{\theta_{w}}{\theta_{\text {sat }}}\right)^{16.37} & \theta_{w} \leq 0.35 \\
K\left(\theta_{w}\right)=1.33 \times 10^{-5}\left(\frac{\theta_{w}}{\theta_{\text {sat }}}\right)^{42.08} & \theta_{w}>0.35
\end{array}
$$

Finite element modelling may be used to solve the above-described unsaturated water transfer in determine for how long the rainwater may reach the Holocene aquifer through the upper semi-permeable unsaturated coverying layer. 
N.V. Hoang and N.D. Roi/Vietnam Journal of Earth Sciences 37 (2015)

3. Finite element modelling water movement in unsaturated-saturated soil

For the seek ease description, $D_{x}$ and $D_{y}$ are used instead of $D_{x}\left(\theta_{w}\right)$ and $D_{y}\left(\theta_{w}\right)$ respectively and $\theta$ is instead of $\theta_{w}$. In FEM methodolgy, temporarily notconsidering the term $\partial \theta_{w} / \partial t$, and using the approximation $\theta \approx \hat{\theta}=\sum_{m=1}^{M} \theta_{m} N_{m}$ we

have the following (Zienkiewics and K. Morgan, 1983):

$$
\int_{\Omega}\left(D_{x} \frac{\partial^{2} \hat{\theta}}{\partial x^{2}}+D_{z} \frac{\partial^{2} \hat{\theta}}{\partial z^{2}}\right) W_{l} d x d z=0
$$

$$
\begin{aligned}
& \int_{\Omega}\left(D_{x} \frac{\partial^{2} \hat{\theta}}{\partial x^{2}}+D_{z} \frac{\partial^{2} \hat{\theta}}{\partial z^{2}}\right) W_{l} d x d z=-\int_{\Omega}\left(D_{x} \frac{\partial \hat{\theta}}{\partial x} \frac{\partial W_{l}}{\partial x}+D_{z} \frac{\partial \hat{\theta}}{\partial z} \frac{\partial W_{l}}{\partial z}\right) d x d z \\
& +\int_{\Gamma}\left(D_{x} \frac{\partial \hat{\theta}}{\partial x} W_{l} \mathbf{N}_{\mathbf{x}}+D_{z} \frac{\partial \hat{\theta}}{\partial z} W_{l} \mathbf{N}_{z}\right) d \Gamma
\end{aligned}
$$

The term $\int_{\Gamma}$ is present only for the elements with the notation $\Gamma_{q}$ for both these boundary types having sides on the boundaries $\Gamma_{q_{c}}$ and $\Gamma_{q_{v c}}$, and

$$
-\int_{\Omega}\left(D_{x} \frac{\partial \hat{\theta}}{\partial x} \frac{\partial W_{l}}{\partial x}+D_{z} \frac{\partial \hat{\theta}}{\partial z} \frac{\partial W_{l}}{\partial z}\right) d x d z+\int_{\Gamma_{q}}\left(D_{x} \frac{\partial \hat{\theta}}{\partial x} W_{l} \mathbf{N}_{\mathbf{x}}+D_{z} \frac{\partial \hat{\theta}}{\partial z} W_{l} \mathbf{N}_{z}\right) d \Gamma=0
$$

Putting $\theta \approx \hat{\theta}=\sum_{m=1}^{M} \theta_{m} N_{m}$ into (14) we have:

$$
\begin{gathered}
-\int_{\Omega}\left(D_{x} \frac{\partial N_{m}}{\partial x} \frac{\partial W_{l}}{\partial x} \theta_{m}+D_{z} \frac{\partial N_{m}}{\partial z} \frac{\partial W_{l}}{\partial z} \theta_{m}\right) d x d z+\int_{\Gamma_{q}}\left(\bar{q}_{c} W_{l} \mathbf{N}_{\mathbf{x}}+\bar{q}_{c} W_{l} \mathbf{N}_{z}\right) d \Gamma=0 \\
\mathbf{K}=-\int_{\Omega}\left(D_{x} \frac{\partial N_{m}}{\partial x} \frac{\partial W_{l}}{\partial x}+D_{y} \frac{\partial N_{m}}{\partial z} \frac{\partial W_{l}}{\partial z}\right) d x d z ; \quad \mathbf{F}=-\int_{\Gamma_{q}}\left(\bar{q}_{c} W_{l} \mathbf{N}_{\mathbf{x}}+\bar{q}_{c} W_{l} \mathbf{N}_{z}\right) d \Gamma
\end{gathered}
$$

$$
\mathrm{K} \theta=\mathrm{F}
$$

Now, comming back to the term $\partial \theta_{w} / \partial t$, which mean the unsteady state condition, we have (17) in the form:

$$
\mathrm{K} \theta-\frac{\mathrm{d} \theta}{\mathrm{dt}}=\mathrm{F}
$$

The temporal differential may be carried out in one of the following three schemes: forward, central and backward.

- Forward schems (Euler)

$$
\left(\frac{1}{\Delta \mathrm{t}_{\mathrm{n}}}+\mathrm{K}\right) \theta^{\mathrm{n}}-\frac{\theta^{\mathrm{n}+1}}{\Delta \mathrm{t}_{\mathrm{n}}}=\mathrm{F}
$$

This scheme is also called explicite since $\theta^{n+1}$ is expressed through $\theta^{n}$ as follows:

$$
\theta^{\mathrm{n}+1}=\left(1+\Delta \mathrm{t}_{\mathrm{n}} \mathrm{K}\right) \theta^{\mathrm{n}}+\mathrm{F}
$$

- Crank-Nicolson scheme (central scheme)

$$
\left(-2+\Delta \mathrm{t}_{\mathrm{n}} \mathrm{K}\right) \theta^{\mathrm{n}+1}=-\left(2+\Delta \mathrm{t}_{\mathrm{n}} \mathrm{K}\right) \theta^{\mathrm{n}}+\mathrm{F}
$$

this scheme is implicit.

- Backward scheme (also implicit):

$$
(\mathrm{K} \Delta \Delta-1) \theta^{\mathrm{n}+1}=\theta^{\mathrm{n}}+\mathrm{F}
$$

The accuracy of the results by FEM required that the sizes of the elements met the condition (Huyakorn and Pinder, 1987): 
Vietnam Journal of Earth Sciences 37 (2015) 355-362

$$
\Delta x_{i} \leq 10 D_{x}(\theta), \Delta y_{i} \leq 10 D_{y}(\theta)
$$

Within the Governmental scientific reasearch study coded NCCB-ĐHUD.2012-G/04, a FEM code had been built for this unsaturation water movement. The block scheme of the FEM for solving the water transfer in unsaturated soil is presented in Figure 4 with the parameters determined by Hart (1972) (Jiunsheng Li and Hiroshi Kawano, 1997). The accuracy of the FEM code had been verified with the results obtaned by Jiunsheng Li and Hiroshi Kawano in 1997 within the education support to doctoral student in Hanoi Water Resources University in 2005.

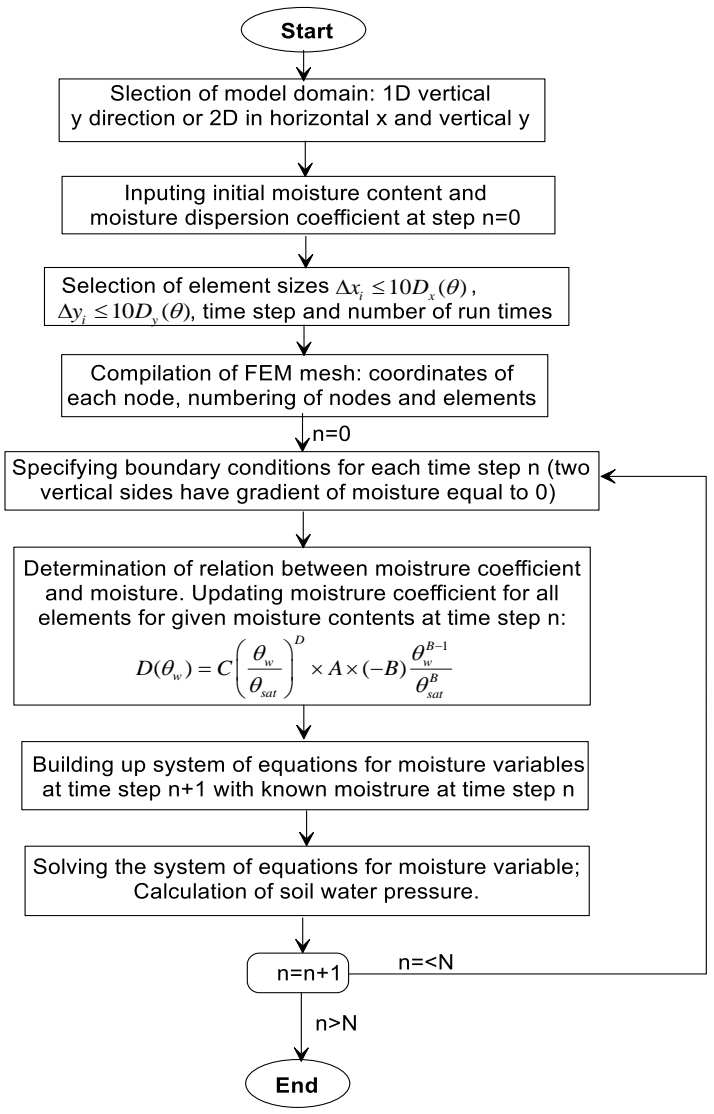

Fig. 4. Block scheme of FEM for unsaturated soil moisture transfer

\section{Simulation scenaria and results}

The thickness of the coverying semi-permeable layer spatially varies. At monitoring well QT119 its thickness is $3 \mathrm{~m}$. However, it is thinner in many other locations and for the purpose of illustration, two thickness cases have been used: $2 \mathrm{~m}$ and $3 \mathrm{~m}$.
Regarding the moisture conditions on the top of the layer (ground surface) and on the bottom (top of the Holocene aquifer), the bottom physically is wet all the time since it has contact with saturated Holocene aquifer. For the top of the layer, it is wet during rainy time or irrigation, otherwise dry.

The initial moisture content along the depth of the unsaturated covering semipermeable layer had been obtained by simulation moisture movement for the wel bottom and dry top of the lyear. The wet moisture content is selected to be $0.36 \mathrm{~g} / \mathrm{cm}^{3}$ $\left(0.36 \mathrm{~cm}^{3} / \mathrm{cm}^{3}\right)$ as it is mostly common for rice paddy field (Hart, 1972; Jiunsheng Li and Hiroshi Kawano, 1997) and as for silty soils liquid limits. The dry moisture is assumed to be $0.26 \mathrm{~g} / \mathrm{cm}^{3}$.

Two cases have been selected for modelling regarding the wet and dry condition on the top of the layer: (1) it is wet all the time (it is true for most time in rainy when excessive humidity exists) and (2) consecutive one wet day and one dry day.

The moistrure content distributions for those four scenaria are presented in the form of depth profiles as in Figurres from 5 to 17.

Figure 15 shows that for the worse case (semipermeable layer has thickness of $3 \mathrm{~m}$ and the rainfall is wet-dry consecutive) the depth of moisture movement thanks to rainwater infiltration is about $1.4 \mathrm{~m}$ during 2 days, while the entire depth profile is saturated after two days of excesive rainfall (such a amount and duration rainfall that make the soil suface fully saturated during two days, that is always available during any annual rainy season).

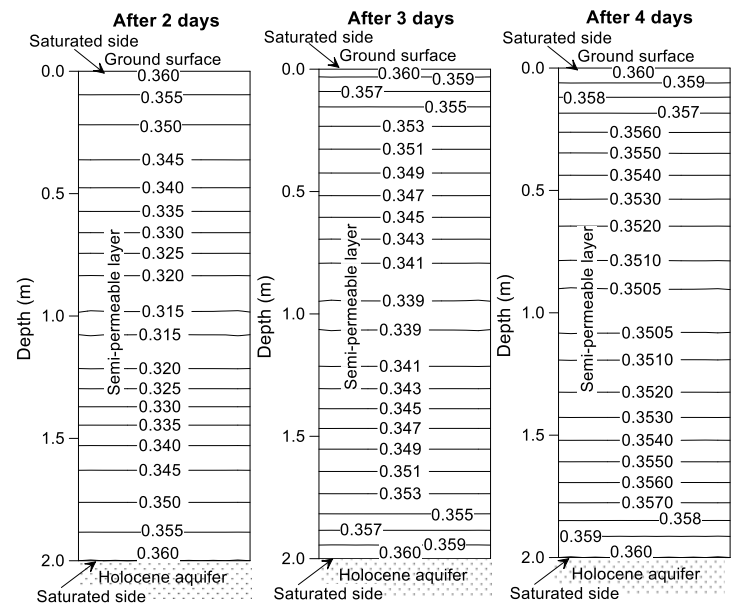

Fig. 5. Moisture distribution after 2,3 and 4 days: semipermeable layer thickness $2 \mathrm{~m}$ 
N.V. Hoang and N.D. Roi/Vietnam Journal of Earth Sciences 37 (2015)

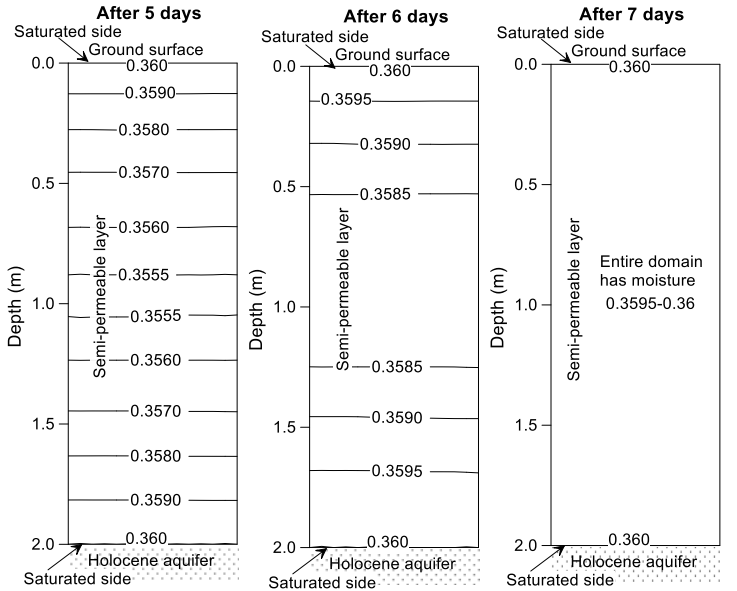

Fig. 6. Moisture distribution after 5, 6 and 7 days: semipermeable layer thickness $2 \mathrm{~m}$
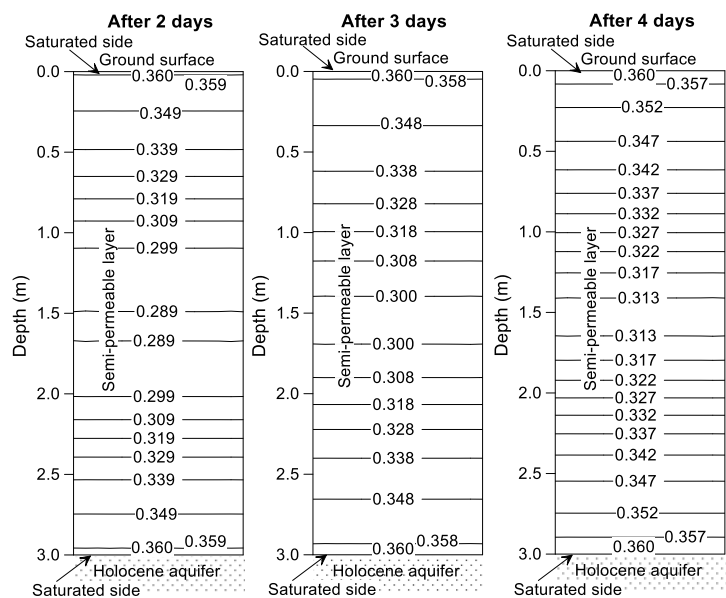

Fig.7. Moisture distribution after 2, 3 and 4 days: semipermeable layer thickness $3 \mathrm{~m}$ After 5 days
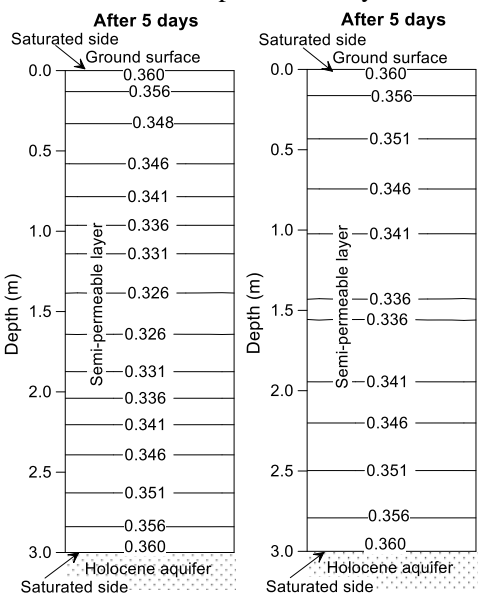

After 7 days Ground surface

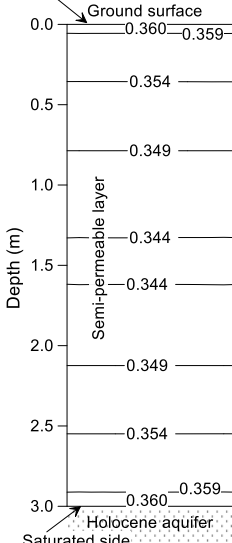

Holocene aquifer Saturated side
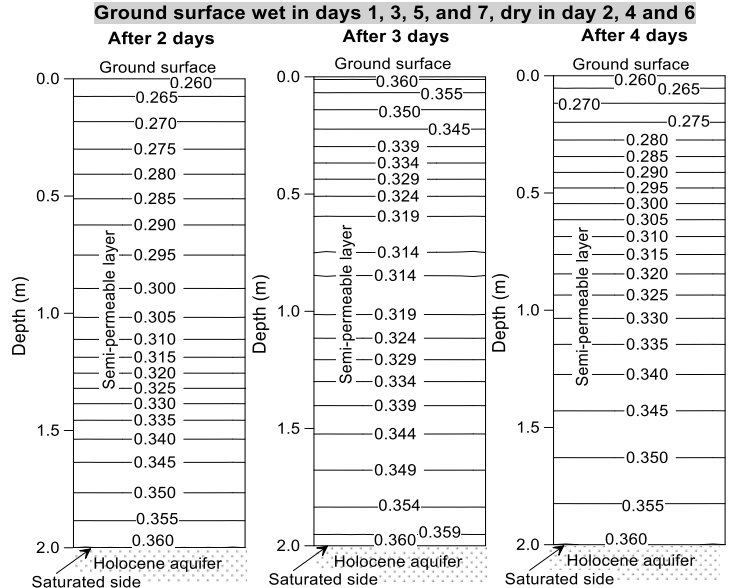

Fig. 9. Moisture distribution after 2, 3 and 4 days: surface ground wet in days $1,3,5$ and 7, semipermeable layer thickness $2 \mathrm{~m}$

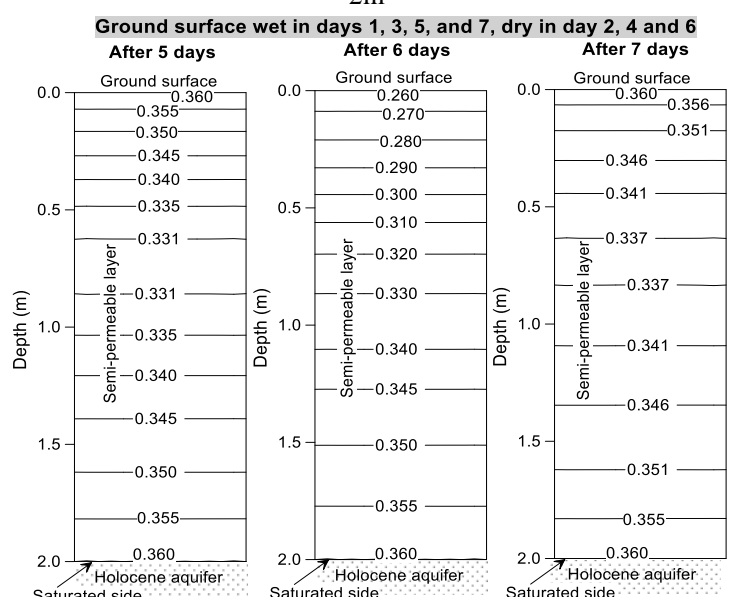

Fig. 10. Moisture distribution after 5, 7 and 7 days: surface ground wet in days $1,3,5$ and 7 , semipermeable layer thickness $2 \mathrm{~m}$

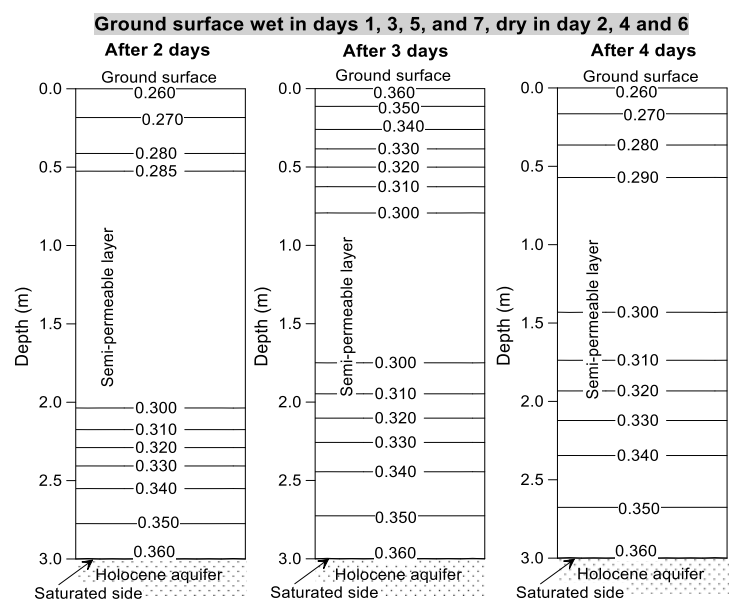

Fig. 11. Moisture distribution after 2, 3 and 4 days: surface ground wet in days 1, 3, 5 and 7, semipermeable layer thickness $3 \mathrm{~m}$ 
Vietnam Journal of Earth Sciences 37 (2015) 355-362

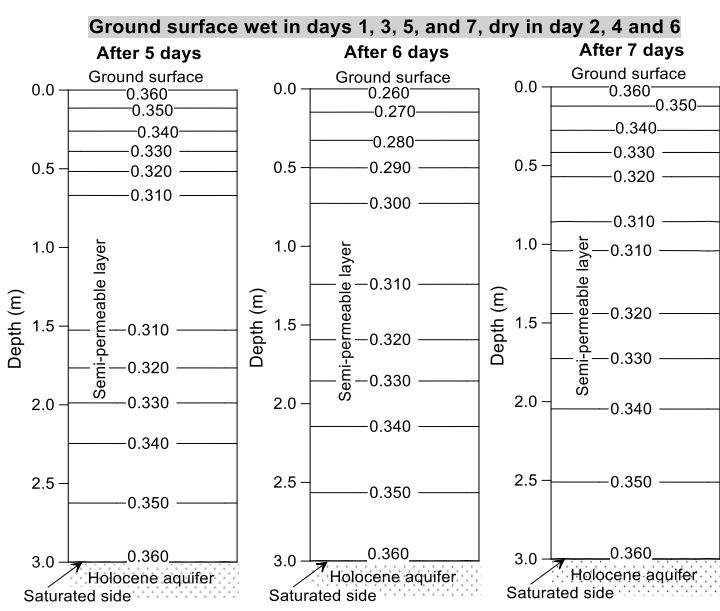

Fig. 12. Moisture distribution after 5, 7 and 7 days: surface ground wet in days 1, 3, 5 and 7, semipermeable layer thickness $3 \mathrm{~m}$

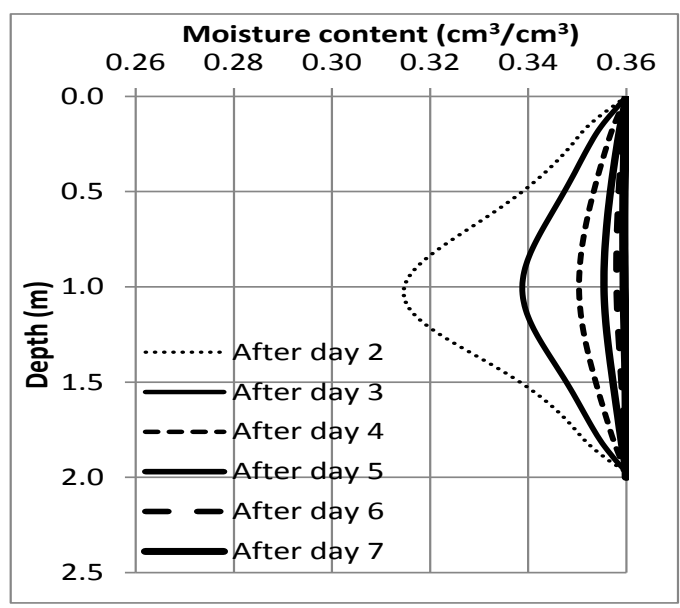

Fig. 13. Moisture distribution curve: layer thickness $2 \mathrm{~m}$,

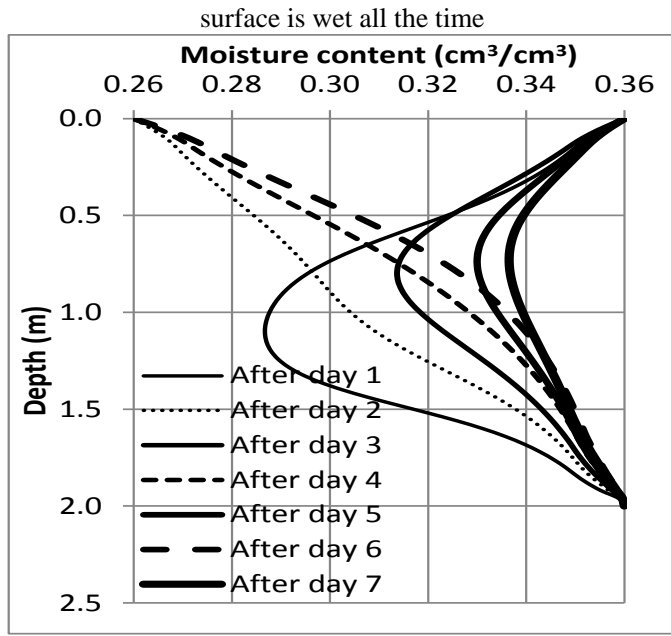

Fig. 14. Moisture distribution curve: layer thickness $2 \mathrm{~m}$, surface is wet-dry consecutive

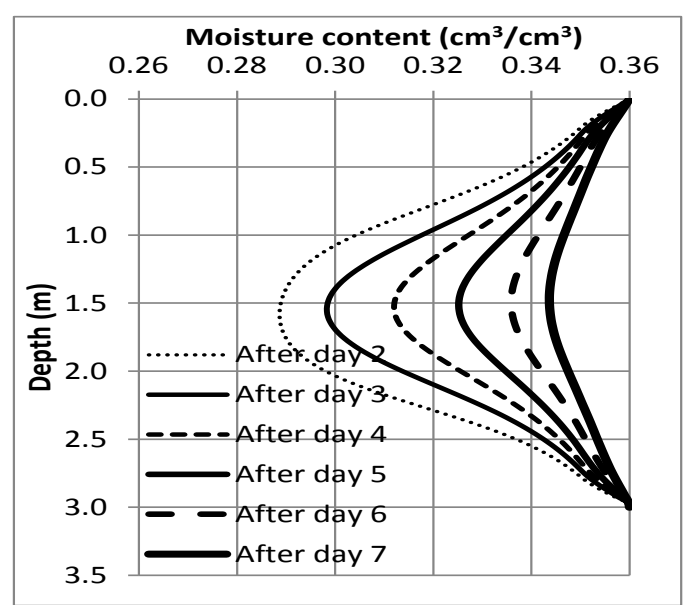

Fig. 15. Moisture distribution curve: layer thickness $3 \mathrm{~m}$, surface is wet all the time

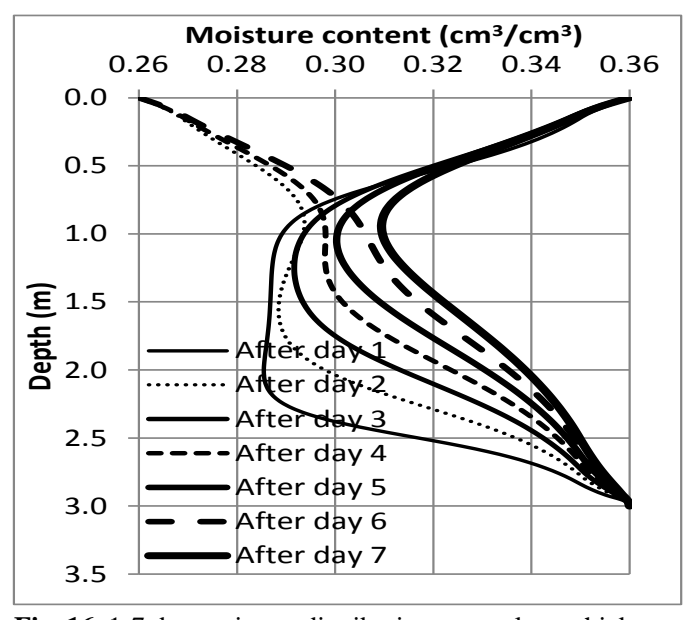

Fig. 16. 1-7 day moisture distribution curve: layer thickness $3 \mathrm{~m}$, surface is wet-dry consecutive

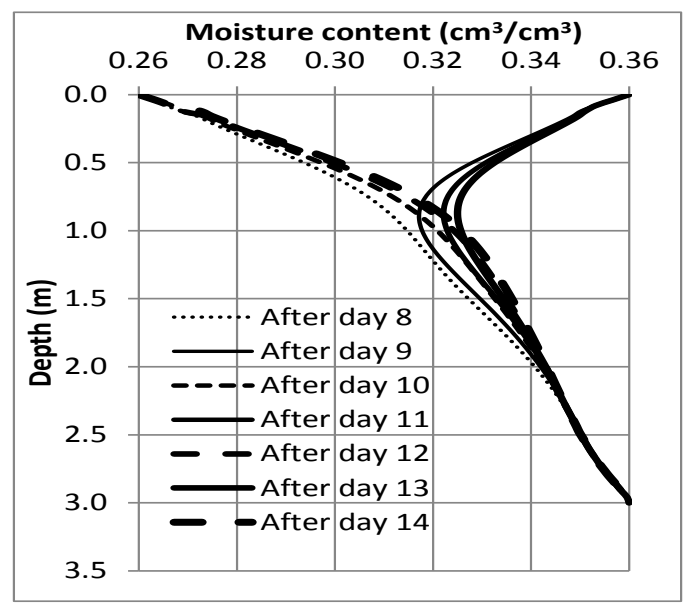

Fig. 17. 8-14 day moisture distribution curve: layer thickness $3 \mathrm{~m}$, surface is wet-dry consecutive 
N.V. Hoang and N.D. Roi/Vietnam Journal of Earth Sciences 37 (2015)

\section{Concluding remarks}

When the saturated condition of the semipermeable layer is observed, the ground surface water is actually supplying the Holocene aquifer. The saturated water flow condition may be assumed if the degree of saturation $90 \%$ or more is observed, as by Omer Nawaf Maaitah (2012) had shown that for silty soils with $90 \%-100 \%$ of degree of saturation has very little difference in capillary height of about $3.4 \mathrm{~cm}$ and close-to-zero suction pressure. Therefore, from the above moisture transfer results, it can be drawn the following remarks:

(i) For continuous wet condition at the top of the semipermeable layer, the moisture of more than $90 \%$ degree of saturation is existing over the entire depth after 3 days for $2 \mathrm{~m}$ of thickness, and 5.5 days for $3 \mathrm{~m}$ of thickness;

(ii) For consecutive wet-dry condition at the top of the semipermeable layer, the moisture of more than $90 \%$ degree of saturation is existing from the depth of $1 \mathrm{~m}$ downwards after 4 days for $2 \mathrm{~m}$ of thickness, and 5.5 days for $3 \mathrm{~m}$ of thickness;

(iii) For consecutive wet-dry condition at the top of the semipermeable layer, the minimal moisture of more than $90 \%$ degree of saturation is existing at the depth of around $0.8 \mathrm{~m}$ after 13 days.

It may discuss that for the study area where the agricultural activities are abundant, the irrigation takes place most time of the year from very dense irrigation system, the wet condition of the ground surface is existing most time. Even the wet ground condition does not exist over the entire area, it is still existing in a large percentage of the province as the rice field and other short-time plant area is about 57\% (Hung Yen Statistic Office, 2014).

It may make conclusion that the rainfall in the area have recharge effect on the Holocene aquifer in term of several day duration of rainfall and my be longest as 15days of duration for discontinuous rainfall. Therefore, weekly, half-month or monthly lag time as the longest duration of rainfall may be considered for the Holocene aquifer recharge estimation based on the rainfall data.

\section{Acknowledgements}

This work had been completed within the scientific research study coded ĐT.NCCBĐHUD.2012-G/04 financially supported by the National Foundation for Science and Technology Development (NAFOSTED) and Vietnam Ministry of Science and Technology.

\section{References}

Vu The Hai, 2005: Study on low flow rate and low pressure sprinkler watering for plants in Vietnam northern mountainous and hilly areas. Doctoral diserstesia thesisHanoi Water Resources University (in Vietnamese).

Huyakorn Pinder, 1987: Computational method in subsurface flow. Academic Press.

Nguyen Van Hoang, 2012-2015: Research study No. NCCBĐHUD.2012-G/04 "Compilation of FEM software for groundwater movement and solute-transport in groundwater - application to the central coastal area".

Jacob Bear and Arnold Verruijt, 1987: Modeling groundwater flow and pollution, D. Reidel Publishing Company, Dordrecht, Holland.

Jiunsheng Li and Hiroshi Kawano, 1997: Sprinkler Water Utilization Efficiency. Journal of International Rainwater Catchment Systems, Vol, 3, No, 1, July, 1997, pp. 41-51.

Polubarinova-Kochina, 1977: Theory of Groundwater Movement. Higher education publishing house. Moscow (in Russian).

Omer Nawaf Maaitah, 2012: Soil-Water Characteristic Curve Model-Silty Sand Soil. Jordan Journal of Civil Engineering, Volume 6, No. 1, 2012

Zienkiewics O.C. and Morgan K., 1983: Finite Elements and Approximation. John Willey \& Sons.

Department of geology and mineral resources-MoNRE. 2013. Groundwater monitoring in Bac Boc Plain. Center for Geological Information and Archive-MoNRE.

Hung Yen Statistic Office, 2014: Hung Yen statistical book year 2013.

National Center for Meteorology and Hydrology-MoNRE, 2013: Meteorological and Hydrological monitoring data. 